\title{
Studies of the Effect of Storage Conditions on Some Pharmaceutical Parameters of Powders and Tablets
}

\author{
Bakre Lateef Gbenga and Yusuf Taiwo
}

Department of Pharmaceutics and Pharmaceutical Technology, Faculty of Pharmacy, Olabisi Onabanjo University, Sagamu, Nigeria

Received: June 18, 2014; Accepted: July 25, 2015; Published (web): January 31, 2016

\begin{abstract}
This study evaluates the effect of storage conditions on some pharmaceutical parameters of powders (paracetamol, corn starch, tragacanth and polyvinyl pyrrolidone) and tablets (paracetamol, metronidazole and vitamin C). For powdered samples, angle of repose, bulk and tapped densities were determined while the tablets were evaluated for hardness, friability and disintegration before and after exposure to various humidity conditions, radiations from telecommunication mast and sunlight at intervals of $24 \mathrm{hrs} \& 1,2,4$ and 8 weeks. The results showed a decrease in the angle of repose for paracetamol, corn starch, polyvinyl pyrollidone and tragacanth powders on exposure to sunlight. There was no significant $(\mathrm{p}>0.05)$ change in the tapped and bulk densities under the different storage conditions over the storage period. No organoleptic changes were observed for any of the samples stored under the environmental conditions over the two-month period. All the tablets stored over the two- month period conformed to the official BP standard for weight uniformity. Paracetamol tablets exposed to $93 \%$ relative humidity $(\mathrm{RH})$ showed significantly lower reduction $(\mathrm{P}<0.05)$ in hardness compared to the other storage conditions. On prolonged exposure of paracetamol and metronidazole tablets to radiation from telecommunication mast, there was a reduction in tablet hardness and the tablets became friable. The observations of the present study reconfirm the role of storage conditions in ensuring the physical stability of pharmaceutical powders and tablets.
\end{abstract}

Key words: Pharmaceutical powders and tablets, relative humidity, sunlight, telecommunication mast radiation, stability

\section{INTRODUCTION}

The quality of pharmaceutical products is affected by many factors, such as the stability of the active ingredient(s), potential interaction between active(s) components and excipients, manufacturing process, dosage form, packaging system, environmental conditions encountered during transport, storage and use, and length of time between manufacture and usage. ${ }^{1,2}$ The physical, chemical and biological properties may be altered during storage leading to deterioration, and decrease in their therapeutic usefulness. In certain cases, such deterioration may result to toxicity of the drug substance. ${ }^{3,4}$ The knowledge of the various storage

Correspondence to: Bakre Lateef Gbenga

E-mail: lateefbakr@yahoo.com

Dhaka Univ. J. Pharm. Sci. 14(2): 147-151, 2015 (December) conditions for individual drug products and the need to provide such optimal storage conditions is therefore of prime importance. Apart from the danger posed by such deteriorated drug substances, there is the problem of economic loss to the manufacturing firms who may need to recall such products. Generally, pharmaceutical products undergo three types of deteriorations namely: physical, chemical and microbial. ${ }^{5,6}$ Chemical deterioration is usually caused by series of chemical reactions involving the active ingredient and other adjuvants. Exposure to environmental conditions such as temperature, humidity, sunlight, $\mathrm{pH}$, moisture and oxygen affect the rate and extent of drug chemical degradation. In addition to the chemical decomposition (hydrolysis, oxidation, isomerisation, polymerisation, photochemical degradation) of the drugs and/or excipients, physical changes to the solid dosage form, 
such as changes in tablet hardness, friability, disintegration and/or the dissolution rate may lead to both altered physical appearance and/or bioavailability of the drug. Chemical and physical degradation of drug substances may change their pharmacological effects, resulting in altered efficacy as well as toxicological consequences.

Since pharmaceuticals are used therapeutically based on their efficacy and safety, they should be stable and maintain their quality until the expiry date. The quality should be maintained during production, storage in warehouse, transportation, and storage in hospital and community pharmacies as well as during patient handling. Therefore, understanding the factors that alter the stability of pharmaceuticals and identifying ways to guarantee their stability are critical. This study aims to investigate the effect of exposure of environmental conditions namely sunlight, various humidity conditions and radiation from telecommunication mast on some commonly used pharmaceutical powders and tablets.

\section{MATERIALS AND METHODS}

Paracetamol powder B.P. and polyvinyl pyrrolidone (PVP K-30) were obtained from BDH Chemicals, UK and Merck, Germany respectively. The salts required for preparing saturated solutions for humidity studies were purchased from Deadsea Chemicals, Israel and A.H.A. Chemicals, China. Corn starch and tragacanth were of pharmaceutical grade. Tablets of paracetamol, vitamin $\mathrm{C}$ and metronidazole were purchased from Watson Pharmaceuticals, Nigeria.

Storage of pharmaceutical powders and tablets. The tablets and powders were stored in stability chambers at $23,43,83,86$, and $93 \%$ relative humidity (RH) provided by the saturated salt solutions of sodium acetate, potassium carbonate, potassium bromide, potassium chloride and potassium nitrate respectively. At time interval of 24 hrs \& 1, 2, 4 and 8 weeks, samples of the powders and tablets were taken for analysis. Some tablets and powders were also exposed to sunlight and radiations from telecommunication mast and were analyzed after 24 hrs \& 1, 2, 4 and 8 weeks of storage.

Physical stability analysis of powder samples. The poured bulk density of each powder was determined by pouring the powder at an angle of $45^{\circ}$ through a funnel into a glass measuring cylinder with a diameter of $21 \mathrm{~mm}$ and a volume of $50 \mathrm{~mL}^{7}$ Determinations were made in triplicate. Tap bulk density was determined by subjecting the powder in a graduated cylinder to 300 taps by a standardized tapping procedure of 38 taps per minute. ${ }^{8}$ The Hausner's ratio was determined as the ratio of the poured bulk volume to the tapped volume. The static angle of repose was measured according to the fixed funnel and free standing cone method as described by Iwuagwu and Onyekwelli. ${ }^{9}$ The flow rate was calculated as the ratio of the mass of the samples to their time of flow. The powders were also assessed for organoleptic changes in colour, odour and appearance.

Physical stability analysis of the tablets. The physical stability of the tablets was assessed at different time intervals ( $24 \mathrm{hrs} \& 2,4$ and 8 weeks) according to the following methods.

Tablet hardness test. The load required to diametrically break the tablet (crushing strength) was determined at room temperature using a Ketan hardness tester. Ten tablets, randomly selected from each batch were used in the test. The value of the load on the guage at this point gives a measure of the tablet crushing strength in Kilogram force $(\mathrm{KgF})$. The crushing strength values were converted to Newton by multiplying the crushing strength in $\mathrm{KgF}$ with 9.8 $(1 \mathrm{kgF}=9.8 \mathrm{~N})$. Determinations were made in triplicate for each batch of the tablet tested.

Tablet friability test. Roche friabilator (Erweka type TA3R) was used to carry out the friability test. Ten (10) tablets from each batch were weighed and then placed on the friabilator, which was then operated for four (4) min at $25 \mathrm{rpm}$ (100 revolutions). The tablets were de-dusted, reweighed and the difference in tablet weight was determined. The percentage weight loss was calculated as the friability. Determinations were made in triplicate. 
Disintegration test. The disintegration time, of the tablets were determined in distilled water at $37 \pm$ $0.5 \mathrm{C}$ using BP Manesty disintegration test unit (Manesty Machines, Poole, U.K). Six tablets from each formulation were taken for the determination of disintegration test. The time taken for all the tablets to disintegrate and go through the wire mesh was recorded. Determinations were made in triplicate.

Data analysis. Percentage relative standard deviations were determined for representation of accuracy in the measurement. Statistical Package for the Social Sciences (version 12) was used for ANOVA analysis to determine the level of significance $(p<0.05)$ of results obtained.

\section{RESULTS AND DISCUSSION}

The impact of various storage conditions on the physicochemical parameters of some pharmaceutical powders are shown in table 1. Tablet hardness, friability and weight variation data of paracetamol, metronidazole and vitamin $\mathrm{C}$ tablets stored under various storage conditions are presented in table 2 while figure 1 highlights the effect of different environmental conditions on the disintegration times of paracetamol tablet.
Physical properties of powders under different storage conditions. The stability parameters of a drug dosage form can be influenced by environmental conditions of storage (temperature, light, air, and humidity), as well as the package components. Angle of repose has been used to characterize the flow properties of powders. ${ }^{10}$ Table 1 shows that there was a decrease in the angle of repose for paracetamol, cornstarch, PVP and tragacanth powders on exposure to sunlight. This might be due to loss of entrapped moisture in the powders as a result of the heat energy of the sun. This consequently results in reduction in interparticulate resistance to flow. There was a significantly lower $(p<0.05)$ reduction in angle of repose of cornstarch powder compared to all the other powders. Powders exposed to telemast radiation exhibited an increase in angle of repose after 2 weeks of exposure, then a reduction after 4 weeks and then an increase after a prolonged period of 8 weeks. There was an increase in the angle of repose of tragacanth gum with storage at $23 \%, 86 \%$ and $93 \% \mathrm{RH}$. This might be due to the fact that tragacanth is a polymeric gum that consists of heterogeneous polysaccharides which contain different highly substituted pectin- like structural elements that absorbs water to form a gel, which will lead to a more cohesive powder. ${ }^{11}$

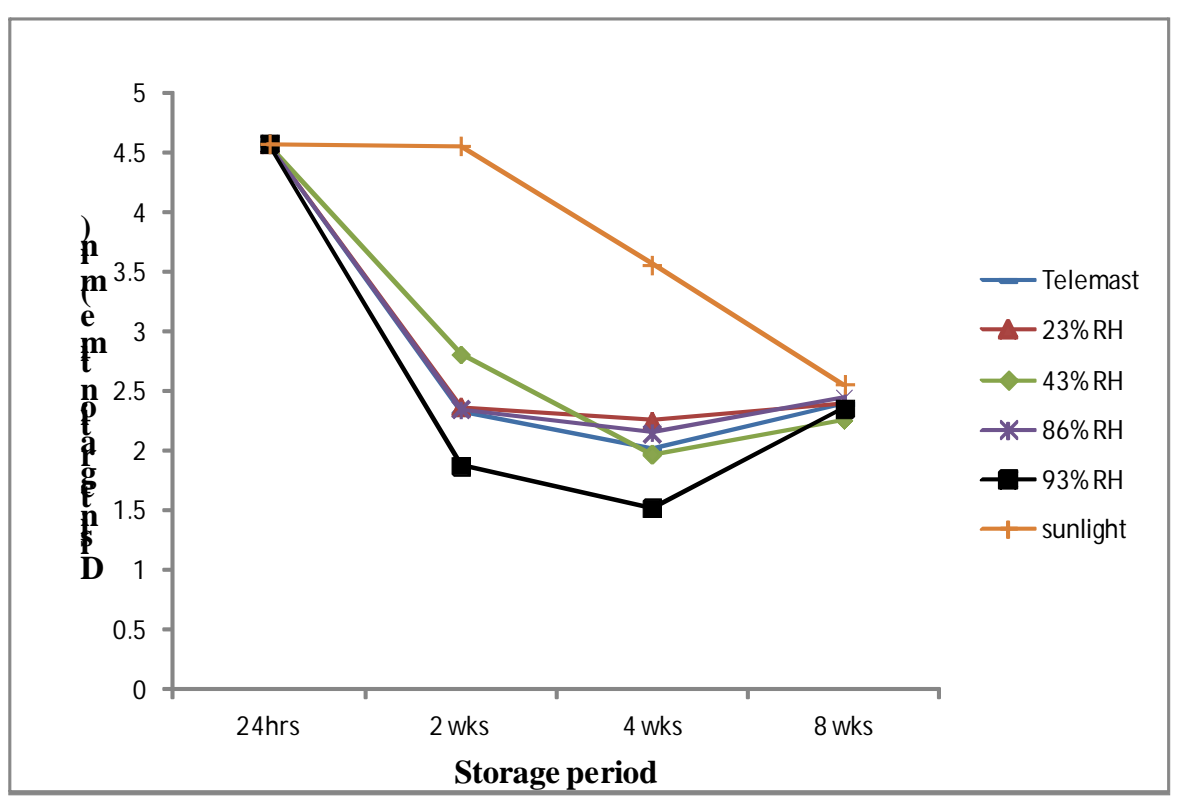

Figure 1. Effect of exposure of different environmental conditions on the disintegration time of paracetamol tablet. 
Table 1. Effect of storage conditions on the physicochemical properties of pharmaceutical powders.

\begin{tabular}{|c|c|c|c|c|c|c|c|c|c|c|c|c|c|}
\hline \multirow[t]{2}{*}{ Drug } & \multirow{2}{*}{$\begin{array}{l}\text { Environmental } \\
\text { factors }\end{array}$} & \multicolumn{4}{|c|}{ Angle of repose $\left(^{\circ}\right)$} & \multicolumn{4}{|c|}{ Bulk density $(\mathrm{g} / \mathrm{ml})$} & \multicolumn{4}{|c|}{ Tapped density $(\mathrm{g} / \mathrm{ml})$} \\
\hline & & $24 \mathrm{hrs}$ & $2 \mathrm{wks}$ & $4 \mathrm{wks}$ & $8 \mathrm{wks}$ & $24 \mathrm{hrs}$ & $2 \mathrm{wks}$ & $4 \mathrm{wks}$ & $8 w k s$ & $24 \mathrm{hrs}$ & $2 \mathrm{wks}$ & $4 \mathrm{wks}$ & $8 w k s$ \\
\hline \multirow[t]{6}{*}{ Paracetamol } & Sunlight & 45.6 & 45.4 & 45.0 & 45.0 & 0.43 & 0.40 & 0.41 & 0.40 & 0.45 & 0.47 & 0.43 & 0.41 \\
\hline & Telecom. mast & 45.6 & 46.4 & 41.5 & 43.0 & $0.43 .$. & 0.46 & 0.45 & 0.42 & 0.45 & 0.45 & 0.51 & 0.45 \\
\hline & $23 \% \mathrm{RH}$ & 45.6 & 48.9 & 48.9 & 49.0 & 0.43 & 0.42 & 0.42 & 0.40 & 0.45 & 0.48 & 0.48 & 0.47 \\
\hline & $43 \% \mathrm{RH}$ & 45.6 & 38.8 & 38.8 & 44.3 & 0.43 & 0.42 & 0.42 & 0.42 & 0.45 & 0.47 & 0.47 & 0.45 \\
\hline & $86 \% \mathrm{RH}$ & 45.6 & 45.4 & 45.4 & 45.0 & 0.43 & 0.42 & 0.42 & 0.45 & 0.45 & 0.49 & 0.49 & 0.51 \\
\hline & $93 \% \mathrm{RH}$ & 45.6 & 39.0 & 39.0 & 40.9 & 0.43 & 0.45 & 0.45 & 0.43 & 0.45 & 0.50 & 0.50 & 0.47 \\
\hline \multirow[t]{6}{*}{ Corn starch } & Sunlight & 45.0 & 36.9 & 36.4 & 36.0 & 0.51 & 0.49 & 0.47 & 0.47 & 0.53 & 0.53 & 0.51 & 0.50 \\
\hline & Telecom. mast & 45.0 & 48.0 & 43.0 & 47.6 & $0.51 .$. & 0.51 & 0.43 & 0.42 & 0.53 & 0.53 & 0.47 & 0.44 \\
\hline & $23 \% \mathrm{RH}$ & 45.5 & 45.8 & 45.9 & 46.0 & 0.51 & 0.50 & 0.48 & 0.44 & 0.53 & 0.50 & 0.53 & 0.48 \\
\hline & $43 \% \mathrm{RH}$ & 45.0 & 45.0 & 41.9 & 48.0 & 0.51 & 0.47 & 0.40 & 0.44 & 0.53 & 0.48 & 0.49 & 0.45 \\
\hline & $86 \% \mathrm{RH}$ & 45.0 & 43.9 & 45.0 & 45.2 & 0.51 & 0.49 & 0.49 & 0.51 & 0.53 & 0.53 & 0.53 & 0.53 \\
\hline & $93 \% \mathrm{RH}$ & 45.0 & 43.9 & 41.8 & 44.0 & 0.51 & 0.48 & 0.47 & 0.40 & 0.53 & 0.50 & 0.50 & 0.44 \\
\hline \multirow[t]{6}{*}{ PVP } & Sunlight & 43.8 & 40.6 & 40.2 & 39.8 & 0.48 & 0.57 & 0.52 & 0.50 & 0.50 & 0.63 & 0.60 & 0.51 \\
\hline & Telecom. mast & 43.8 & 52.2 & 41.6 & 41.0 & 0.48 & 0.53 & 0.50 & 0.50 & 0.50 & 0.54 & 0.48 & 0.53 \\
\hline & $23 \% \mathrm{RH}$ & 43.8 & 45.0 & 42.1 & 41.7 & 0.48 & 0.54 & 0.53 & 0.48 & 0.50 & 0.57 & 0.57 & 0.51 \\
\hline & $43 \% \mathrm{RH}$ & 43.8 & 41.6 & 40.9 & 40.7 & 0.48 & 0.53 & 0.53 & 0.50 & 0.50 & 0.57 & 0.57 & 0.53 \\
\hline & $86 \% \mathrm{RH}$ & 43.8 & 38.7 & 34.0 & 34.0 & 0.48 & 0.56 & 0.43 & 0.43 & 0.50 & 0.61 & 0.53 & 0.53 \\
\hline & $93 \% \mathrm{RH}$ & 43.8 & 46.9 & 35.7 & 50.6 & 0.48 & 0.51 & 0.57 & 0.59 & 0.50 & 0.55 & 0.61 & 0.60 \\
\hline \multirow[t]{6}{*}{ Tragacanth } & Sunlight & 38.0 & 37.1 & 37.0 & 36.5 & 0.59 & 0.55 & 0.55 & 0.53 & 0.65 & 0.60 & 0.56 & 0.51 \\
\hline & Telecom. mast & 38.0 & 44.0 & 35.5 & 41.0 & 0.59. & 0.59 & 0.61 & 0.56 & 0.65 & 0.63 & 0.67 & 0.69 \\
\hline & $23 \% \mathrm{RH}$ & 38.0 & 37.9 & 39.0 & 41.0 & 0.59 & 0.63 & 0.64 & 0.53 & 0.65 & 0.67 & 0.69 & 0.59 \\
\hline & $43 \% \mathrm{RH}$ & 38.0 & 36.0 & 32.2 & 44.6 & 0.59 & 0.63 & 0.61 & 0.54 & 0.65 & 0.63 & 0.69 & 0.63 \\
\hline & $86 \%$ RH & 38.0 & 39.8 & 40.0 & 40.2 & 0.59 & 0.61 & 0.54 & 0.54 & 0.65 & 0.65 & 0.61 & 0.57 \\
\hline & $93 \% \mathrm{RH}$ & 38.0 & 39.4 & 45.0 & 46.0 & 0.59 & 0.59 & 0.54 & 0.48 & 0.65 & 0.63 & 0.57 & 0.51 \\
\hline
\end{tabular}

Table 2. Effect of storage conditions on the physical parameters of tablets.

\begin{tabular}{|c|c|c|c|c|c|c|c|c|c|c|c|c|c|}
\hline \multirow[t]{2}{*}{ Drug } & \multirow{2}{*}{$\begin{array}{l}\text { Environmental } \\
\text { factors }\end{array}$} & \multicolumn{3}{|c|}{ Tablet hardness $(\mathrm{kg} / \mathrm{F})$} & \multicolumn{5}{|c|}{ Friability $(\%)$} & \multicolumn{4}{|c|}{ Weight variation $(\%)$} \\
\hline & & $24 \mathrm{hrs}$ & $2 w k s$ & $4 \mathrm{wks}$ & $8 w k s$ & $24 \mathrm{hrs}$ & $2 w k s$ & $4 \mathrm{wks}$ & $8 w k s$ & $24 \mathrm{hrs}$ & $2 w k s$ & $4 \mathrm{wks}$ & $8 w k s$ \\
\hline \multirow[t]{6}{*}{ Paracetamol } & Sunlight & 9.92 & 9.92 & 9.94 & 9.94 & 0.69 & 0.08 & 0.11 & 0.13 & 0.58 & 0.57 & 0.57 & 0.57 \\
\hline & Telecom. mast & 9.92 & 9.03 & 8.60 & 7.80 & 0.69 & 0.09 & 0.18 & 0.17 & 0.58 & 0.57 & 0.57 & 0.58 \\
\hline & $23 \% \mathrm{RH}$ & 9.92 & 8.80 & 8.00 & 7.47 & 0.69 & 0.09 & 0.09 & 0.09 & 0.58 & 0.56 & 0.56 & 0.56 \\
\hline & $43 \% \mathrm{RH}$ & 9.92 & 8.12 & 8.23 & 7.90 & 0.69 & 0.26 & 0.26 & 0.26 & 0.58 & 0.57 & 0.58 & 0.57 \\
\hline & $86 \% \mathrm{RH}$ & 9.92 & 8.30 & 8.37 & 8.19 & 0.69 & 0.58 & 0.35 & 0.31 & 0.58 & 0.57 & 0.57 & 0.57 \\
\hline & $93 \% \mathrm{RH}$ & 9.92 & 5.95 & 6.80 & 7.06 & 0.69 & 0.35 & 0.45 & 0.43 & 0.58 & 0.58 & 0.57 & 0.58 \\
\hline \multirow[t]{6}{*}{ Metronidazole } & Sunlight & 5.57 & 5.08 & 5.08 & 5.00 & 0.95 & 0.08 & 0.10 & 0.09 & 0.56 & 0.59 & 0.58 & 0.57 \\
\hline & Telecom. mast & 5.57 & 5.08 & 4.90 & 3.90 & 0.95 & 0.17 & 0.19 & 0.74 & 0.56 & 0.56 & 0.56 & 0.56 \\
\hline & $23 \% \mathrm{RH}$ & 5.57 & 4.50 & 4.30 & 3.18 & 0.95 & 0.99 & 0.97 & 0.79 & 0.56 & 0.55 & 0.56 & 0.55 \\
\hline & $43 \% \mathrm{RH}$ & 5.57 & 3.30 & 2.70 & 2.85 & 0.95 & 0.51 & 0.22 & 0.94 & 0.56 & 0.56 & 0.57 & 0.57 \\
\hline & $86 \% \mathrm{RH}$ & 5.57 & 4.92 & 4.40 & 3.90 & 0.95 & 0.25 & 0.64 & 0.65 & 0.56 & 0.56 & 0.55 & 0.55 \\
\hline & $93 \% \mathrm{RH}$ & 5.57 & 3.50 & 3.90 & 3.18 & 0.95 & 0.79 & 0.26 & 0.74 & 0.56 & 0.56 & 0.56 & 0.57 \\
\hline \multirow[t]{6}{*}{ Vitamin C } & Sunlight & 2.07 & 2.05 & 2.00 & 1.84 & 0.15 & 0.16 & 0.18 & 0.20 & 0.31 & 0.31 & 0.30 & 0.31 \\
\hline & Telecom. mast & 2.07 & 1.87 & 2.20 & 1.44 & 0.15 & 0.15 & 0.16 & 0.33 & 0.30 & 0.30 & 0.30 & 0.29 \\
\hline & $23 \% \mathrm{RH}$ & 2.07 & 1.40 & 1.00 & 0.90 & 0.15 & 0.16 & 0.33 & 0.52 & 0.30 & 0.30 & 0.30 & 0.30 \\
\hline & $43 \% \mathrm{RH}$ & 2.07 & 0.87 & 0.70 & 0.78 & 0.15 & 0.16 & 0.16 & 0.47 & 0.30 & 0.30 & 0.30 & 0.31 \\
\hline & $86 \% \mathrm{RH}$ & 2.07 & 2.10 & 1.37 & 1.19 & 0.15 & 0.15 & 0.65 & 0.62 & 0.30 & 0.32 & 0.31 & 0.30 \\
\hline & $93 \% \mathrm{RH}$ & 2.07 & 0.14 & 0.64 & 0.78 & 0.15 & 0.15 & 0.16 & 0.64 & 0.30 & 0.31 & 0.30 & 0.31 \\
\hline
\end{tabular}

Generally there was an observed decrease in angle of repose over the storage period at HR above $23 \%$. This suggests that the critical relative humidity for the powders which is the relative humidity above which a powder starts to absorbs moisture (and gain weight $)^{12}$ is $23 \%$. Therefore, above $23 \% \mathrm{RH}$ there 
was absorption of moisture and consequently increased resistance to free flow of particles of the powders. Table 1 shows that there was no significant ( $>>0.05$ ) change in the tapped and bulk density under the different storage conditions over the storage period.

Physical stability of tablets. No organoleptic changes were observed for any of the samples stored under the environmental conditions over the twomonth period. All the tablets stored over the twomonth period conformed to the official BP standard for weight uniformity i.e not more than two of the individual masses of 20 units taken at random deviated from the average mass by more than $5 \%$ (i.e. for an uncoated tablet of greater than $250 \mathrm{mg}$ average mass) and none deviated by more than twice that percentage. On exposure to sunlight over the storage period, there was a decrease in tablet hardness for metronidazole and vitamin $\mathrm{C}$ tablets but an increase for paracetamol tablet. Paracetamol tablets exposed to $93 \%$ RH showed significantly lower reduction $(\mathrm{P}<0.05)$ in hardness compared to the other storage conditions. On prolonged exposure of paracetamol and metronidazole tablets to radiation from telecommunication mast, there was a reduction in tablet hardness and increase of friability. Friability values for vitamin $\mathrm{C}$ tablets stored under the various conditions indicate a general increase in friability over the period of storage. The effect of the various environmental conditions on the disintegration time of paracetamol tablets is shown in figure 1. There was a general reduction in disintegration time with storage for all the environmental factors tested. This might be due to absorption of moisture over time which consequently resulted in swelling and breaking up of the tablet when the tablets were placed in the disintegration medium. Paracetamol tablets exposed to $93 \% \mathrm{RH}$ showed the greatest reduction in disintegration time. This was in conformity with the hardness values recorded because the tablets were softest at this humidity.

\section{CONCLUSION}

This study emphasizes the importance of proper protection of pharmaceutical powders and tablets from high temperature, radiation from telecommunication mast and humidity conditions for maintaining physical integrity and stability of the product within the stipulated shelf life.

\section{Declaration of interest}

The authors report no conflicts of interest.

\section{REFERENCES}

1. Troy, D.B. 2006. Remington: The science and Practice of Pharmacy. $21^{\text {st }}$ Ed. Philadelphia: Lippincott, Williams \& Wilkins, p. 2393.

2. US Pharmacopeia/National Formulary (USP-28/NF-23). Pharmaceutical stability. Rockville: United States Pharmacopeial Convention; 2005.

3. Carter, S.J. 1986. Tutorial Pharmacy, C.B.S. Publishers, India, pp. 68-69.

4. Martins, A., Swarbrick, J. and Cammarata, A. 1983. Physical Pharmacy, Lea and Febiger, Philadelphia, pp. 386-389.

5. Sharpe, J.R. 1983. Guide to good manufacturing practice. HMSO, London

6. Flynn, G.L. 1979. In Modern Pharmaceutics, Banker, G.S and Rhodes, C.T, Eds., Marcel Dekker, New York, p. 263.

7. Paronen, P. and Juslin, M. 1983. Compressional characteristics of four starches. J. Pharm. Pharmacol. 35, 627-635.

8. British Standard 1460. London. British Standard Institution. 1970

9. Iwuagwu, M.A. and Onyekweli, A.O. 2002. Preliminary investigation into the use of pleutorus tuber- regium powder as a tablet disintegrant. Trop. J. Pharm. Res. 1, 29-37.

10. Shiihii, S.U., Musa, H., Bhatia, P.G. and Martins, E. 2011. Evaluation of physicochemical properties of Eleusine coracana starch . Nig. J. Pharm. Sci. 10, 91-102

11. Gavlighi, H.A., Meyer, A.S. and Mikkelsen, J.D. 2013. Tragacanth gum: functionality and prebiotic potential. Agro. Food Industry Hi. Tech. 24, 46-48

12. Kuu, W., Chilamkurti, R. and Chen, C. 1998. Effect of relative humidity and temperature on moisture sorption and stability of sodium bicarbonate powder. Int. J. Pharm. 166, $167-175$ 